\title{
Immunization Status of Under-5 Children in A Rural Community in Nigeria
}

\author{
Adekunle S Adediran ${ }^{1}$,Nnamdi B Onyire ${ }^{2}$,Virginia O Guvuoke ${ }^{1}$, \\ Ezeanosike Obum ${ }^{2}$, Onyinye U Anyanwu ${ }^{2}$ \\ ${ }^{I}$ Department Of Paediatrics, Federal Medical Centre, Abeokuta, \\ ${ }^{2}$ Department Ofpaediatrics, Federal Teaching Hospital, Abakaliki
}

\begin{abstract}
Aim: A survey was carried out to assess the immunization status of under-5 children in a rural community and its association with mother's educational status and age.

Methods: Trained personnel administered pre-tested questionnaires to the mothers of the selected children who met the inclusion criteria.

Results: Complete immunization rate is $72.2 \%$, $83.3 \%$ for males; $69.5 \%$ for females. There is positive correlation between educational status of mothers and immunization of their children. Children of mothers aged less than 20 years of age and of those over 50 years of age have 100\% vaccination rate for most of the vaccines but as low as $47.7 \%$ among children of mothers aged 20-50 years.

The commonest reason for failure of mothers to immunize their children is mother's illness.

Conclusion: complete immunization occurred more in boys than in Girls. Maternal age, education and illness affected immunization status of children.

Keywords: Immunization, Children, Rural, Nigeria

What is already known on this topic Under-5 mortality rate remains high especially in developing countries of the world 6 Immunization rate is low in Nigeria8 Improved immunization will reduce childhood morbidity and mortality 4,5

What this paper adds

Complete immunization rate in this rural community is $72.2 \%$ Age, education, and illness of mothers affect the rate of immunization in their children Mother's illness is the commonest reason for missed opportunity to immunize their children
\end{abstract}

\section{Introduction}

Immunization, a key component of child survival strategies, is among the most cost-effective public health tools for disease control worldwide. 1, 2,3 Successful immunization programme anywhere in the world is rewarded with reduction in childhood morbidity and mortality.4,5The impact is potentially more significant in developing countries because of higher population of under-5 children, high infectious disease burden and poor health infrastructure. Currently, in the developing world, immunization is estimated to prevent about 3 million childhood mortality yearly but if immunization programmes are strengthened, this number could increase to 5 million. 8 Sadly, it's in these same countries that the level of immunization coverage and therefore its impact on the health indices is abysmal.

Today, about 6.5 million under- 5 children die yearly; 2.5 million from vaccine preventable diseases. About half of these (3.2 million) are from sub-Saharan Africa. In Nigeria, the under-5 mortality rate is $124 / 1000$ live births while over 827,000 children under 5 perish annually. 6 Twenty-two percent of these are due to vaccine preventable diseases.7

In Nigeria, $25 \%$ of children age $12-23$ months are fully immunized with the highest of $62.4 \%$ in Imo state and the lowest of $1.4 \%$ in Sokoto state. 8 Thus, despite the massive potential benefits of immunization in Nigeria, many children are still un-immunized. It is in view of this that this community-based cross-sectional study was undertaken to determine the immunization status of under-5 children at Imala, a rural community in Ogun state.

\section{Subjects And Methods}

This was a cross-sectional study carried out at Imala in Abeokuta North Local Government area of Ogun state in April 2014. Approval of the Hospital Research Ethics committee was obtained for the study. Imala is a rural community with a total population of 19,723 . The number of children aged 0-59 months, constituting $25 \%$ of the total population was about 4,930 . 
The investigating team visited the traditional ruler of Imala who then invited all his Chiefs to the palace for briefing by the team leader. The traditional Chiefs were mandated to invite all women with at least one child under-5 years of age to the palace ground at an agreed date. Other traditional means of communication were also employed by the traditional ruler. Systematic random sampling method was employed whereby only odd numbered respondents were chosen. All the children of these women aged under-5 years were then recruited for the study until the minimum sample size was attained. The 28-item pre-tested questionnaires were then administered by research assistants who had been properly trained before commencing the study.

\section{Results}

A total of 312 children were recruited into the study. The socio-demographic characteristics of the respondents are represented in table I.

Table 1: Demographic characteristics of the respondents

\begin{tabular}{|l|l|l|}
\hline Variable & Frequency( N=312) & Percentage (\%) \\
\hline Sex & \multicolumn{2}{|l|}{} \\
\hline Male & \multicolumn{1}{|l|}{} & \multicolumn{1}{l|}{} \\
\hline Female & 174 & 55.8 \\
\hline Fathers occupation & 138 & 44.2 \\
\hline Technicians, skilled artisans etc & \multicolumn{2}{|l|}{} \\
\hline Unskilled workers & 126 & 40.4 \\
\hline Mother's Education & 186 & 59.6 \\
\hline University & \multicolumn{2}{|l|}{} \\
\hline Secondary or tertiary & 18 & 5.8 \\
\hline Primary or None & 132 & 42.3 \\
\hline Mother's age & 162 & 51.9 \\
\hline$<20$ & & \\
\hline $20-29$ & 18 & 5.8 \\
\hline $30-39$ & 156 & 50.0 \\
\hline $40-49$ & 96 & 30.8 \\
\hline $50-59$ & 30 & 9.6 \\
\hline Socio-economic Status & 12 & 3.8 \\
\hline Middle & & \\
\hline Lower & 84 & 26.9 \\
\hline & 228 & 73.1 \\
\hline
\end{tabular}

\section{Uptake Of Vaccines}

There was a relatively high uptake of all the vaccines administered at birth: BCG and OPV0 94.2\%; Hepatitis B vaccine $92.3 \%$. The uptake progressively decreased with age: OPV1 $-88.5 \%$; OPV2 - 84.6\% and OPV3 $-76.9 \%$. Measles and yellow fever vaccines had uptakes of $55.1 \%$ and $51.95 \%$ respectively. This trend is illustrated in figure 1

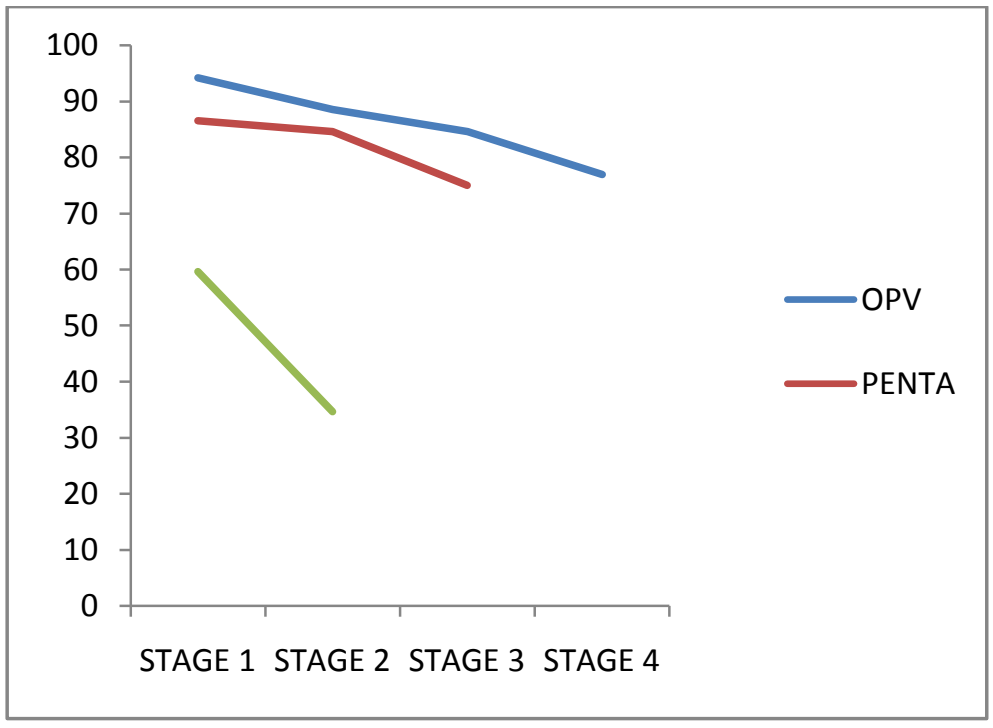

Fig1

\section{Mother's Educational Status}

As illustrated in the table II the uptake of all the vaccines increased with the mother's educational status. In the case of oral polio vaccine 150 (92.6\%) of children who got the vaccine had mothers with only primary or no education, $126(95.5 \%)$ of children who got the vaccine had mothers with up to secondary 
education only while $18(100 \%)$ of children who got the vaccine had mothers with tertiary education. The difference was however not statistically significant.The difference in uptake of immunization with other antigens by the children were also not significant across the various educational levels of the mothers, However, a significant difference was noticed for Vitamin A. The uptake of the first dose of vitamin A was $65 \%$ by children of mothers with primary education, $80 \%$ by children of mothers with secondary education and $92.3 \%$ by children of mothers with tertiary education. For the second dose of vitamin A the figures were $49.5 \%$, $50.8 \%$ and $75 \%$ respectively.

Table2 Uptake of vaccines and mother's education

\begin{tabular}{|c|c|c|c|}
\hline \multirow[t]{2}{*}{ Vaccine } & \multicolumn{3}{|c|}{ Mother's Education } \\
\hline & Primary N(\%) & Secondary $\mathrm{N}(\%)$ & Tertiary $\mathrm{N}(\%)$ \\
\hline \multicolumn{4}{|l|}{ Topv0 } \\
\hline Given & $150(92.6)$ & $126(95.5)$ & $18(100.0)$ \\
\hline Not Given & $12(7.4)$ & $6(4.5)$ & $0(0.0)$ \\
\hline Total & $162(100.0)$ & $132(100.0)$ & $18(100.0)$ \\
\hline \multicolumn{4}{|l|}{ Bcg Vaccine } \\
\hline Given & $150(92.6)$ & $126(95.5)$ & $18(100.0)$ \\
\hline Not Given & $12(7.4)$ & $6(4.5)$ & $0(0.0)$ \\
\hline Total & $162(100.0)$ & $132(100.0)$ & $18(100.0)$ \\
\hline \multicolumn{4}{|l|}{ Measles } \\
\hline Given & $66(73.3)$ & $90(83.3)$ & $6(100.0)$ \\
\hline Not Given & $24(26.7)$ & $18(16.7)$ & $0(0.0)$ \\
\hline Total & $90(100.0)$ & $108(100.0)$ & $6(100.0)$ \\
\hline \multicolumn{4}{|l|}{ Penta3 } \\
\hline Given & $120(76.9)$ & $102(81.0)$ & $12(100.0)$ \\
\hline Not Given & $36(23.1)$ & $24(19.0)$ & $0(0.0)$ \\
\hline Total & $156(100.0)$ & $126(100.0)$ & $12(100.0)$ \\
\hline \multicolumn{4}{|l|}{ Vitamina2 } \\
\hline Given & $48(49.5)$ & $54(50.5)$ & $6(75.0)^{*}$ \\
\hline Not Given & $49(50.5)$ & $53(49.5)$ & $2(25.0)$ \\
\hline Total & $97(100.0)$ & $107(100.0)$ & $8(100.0)$ \\
\hline
\end{tabular}

\section{Mother's Age}

The uptake was generally higher (100\%) for children whose mothers are less than 20 years old and children whose mothers are over 40 years old but much lower for mothers aged 20-49 years (72\%-83\%). The figures were much higher for first and second doses of vitamin A.

Table3 Uptake of vaccines and mother's age

\begin{tabular}{|l|l|l|l|l|l|}
\hline \multirow{2}{*}{ Vaccine } & \multicolumn{4}{|l|}{ Mother's Age (Years) } \\
\cline { 2 - 6 } & $\begin{array}{l}<0 \\
\mathrm{~N}(\%)\end{array}$ & $20-29 \mathrm{~N}(\%)$ & $\begin{array}{l}30-39 \\
\mathrm{~N}(\%)\end{array}$ & $40-49 \mathrm{~N}(\%)$ & $\begin{array}{l}50-59 \\
\mathrm{~N}(\%)\end{array}$ \\
\hline Opv0 & & & & & \\
\hline Given & $18(100.0)$ & $144(92.3)$ & $90(93.8)$ & $30(100.0)$ & $12(100.0)$ \\
\hline Not Given & $0(0.0)$ & $12(7.7)$ & $6(6.2)$ & $0(0.0)$ & $0(0.0)$ \\
\hline Total & $18(100.0)$ & $156(100.0)$ & $96(100.0)$ & $30(100.0)$ & $12(100.0)$ \\
\hline Bcg Vaccine & & & & & \\
\hline Given & $18(100.0)$ & $144(92.3)$ & $90(93.8)$ & $30(100.0)$ & $12(100.0)$ \\
\hline Not Given & $0(0.0)$ & $12(7.7)$ & $6(6.2)$ & $0(0.0)$ & $0(0.0)$ \\
\hline Total & $18(100.0)$ & $156(100.0)$ & $96(100.0)$ & $30(100.0)$ & $12(100.0)$ \\
\hline Measles & & & & & \\
\hline Given & $12(100.0)$ & $72(80.0)$ & $48(72.7)$ & $12(100.0)$ & $12(100.0)$ \\
\hline Not Given & $0(0.0)$ & $18(20.0)$ & $18(27.3)$ & $0(0.0)$ & $0(0.0)$ \\
\hline Total & $12(100.0)$ & $90(100.0)$ & $66(100.0)$ & $12(100.0)$ & $12(100.0)$ \\
\hline Penta3 & & & & & \\
\hline Given & $18(100.0)$ & $114(79.2)$ & $72(80.0)$ & $18(60.0)$ & $12(100.0)^{*}$ \\
\hline Not Given & $0(0.0)$ & $30(20.8)$ & $18(20.0)$ & $12(40.0)$ & $0(0.0)$ \\
\hline Total & $18(100.0)$ & $144(100.0)$ & $90(100.0)$ & $30(100.0)$ & $12(100.0)$ \\
\hline Vitamina2 & & & & & \\
\hline Given & $6(70.5)$ & $48(47.5)$ & $24(36.4)$ & $18(72.0)$ & $12(100.0)$ \\
\hline Not Given & $2(25.0)$ & $53(52.5)$ & $42(63.6)$ & $7(28.0)$ & $0(0.0)$ \\
\hline Total & $8(100.0)$ & $101(100.0)$ & $66(100.0)$ & $25(100.0)$ & $12(100.0)$ \\
\hline
\end{tabular}

Values with superscript $*$ are significantly different in a row 


\section{Reasons For Failure To Immunize}

One hundred and two doses of vaccines were missed due to mothers' illness while 60 doses were missed as a result of fear of reactions. The third commonest reason was that mothers claimed they were unaware of the need to return for immunizations. Thirty doses were missed because vaccines were postponed till another time by health workers. Thirty doses were missed because the vaccines were not available while 18 doses were missed because the mothers were too busy. No mother claimed to be unaware of the need for immunization.

Table4 Reasons for failure to immunize

\begin{tabular}{|c|c|c|c|c|c|c|c|c|c|c|}
\hline \multirow{2}{*}{$\begin{array}{l}\text { Responses } \\
\text { respondents }\end{array}$} & \multicolumn{10}{|c|}{ Different Immunization Types } \\
\hline & $\mathrm{OPV}_{0}$ & $\mathrm{HBV}$ & $\begin{array}{l}\text { BCG } \\
\text { VACCINE }\end{array}$ & $\mathrm{OPV}_{1}$ & $\mathrm{PENTA}_{1}$ & $\mathrm{OPV}_{2}$ & $\mathrm{PENTA}_{2}$ & $\mathrm{OPV}_{3}$ & MEASLES & $\begin{array}{l}\text { YELLOW } \\
\text { FEVER }\end{array}$ \\
\hline Fear of Reactions & $6(33.3)$ & $6(25.0)$ & $6(25.0)$ & $6(16.7)$ & $6(16.7)$ & $6(12.5)$ & $6(12.5)$ & $6(8.3)$ & $6(4.0)$ & $6(4.0)$ \\
\hline $\begin{array}{l}\text { Illness of mother } \\
\text { Unaware of the need to }\end{array}$ & $12(66.7)$ & $6(25.0)$ & $6(25.0)$ & $6(16.7)$ & $12(33.3)$ & $12(25.0)$ & $12(25.0)$ & $12(16.7)$ & $12(8.0)$ & $12(8.0)$ \\
\hline return & & $6(25.0)$ & $6(25.0)$ & $6(16.7)$ & $6(16.7)$ & $6(12.5)$ & $6(12.5)$ & $6(8.3)$ & $6(4.0)$ & $6(4.0)$ \\
\hline Mother too busy & & $6(25.0)$ & $6(25.0)$ & $6(16.7)$ & & & & & & \\
\hline Not due & & & & $12(33.3)$ & $12(33.3)$ & $18(37.5)$ & $18(37.5)$ & $18(25.0)$ & $108(72.0)$ & $108(72.0)$ \\
\hline Postponed till another time & & & & & & $6(12.5)$ & $6(12.5)$ & $18(25.0)$ & & \\
\hline Not available & & & & & & & & $6(8.3)$ & $12(8.0)$ & $12(8.0)$ \\
\hline $\begin{array}{l}\text { Illness of Child } \\
\text { Unaware of the need for } \\
\text { immunization }\end{array}$ & & & & & & & & $6(8.3)$ & $6(4.0)$ & $6(4.0)$ \\
\hline Total & 18 & 24 & 24 & 36 & 36 & 48 & 48 & 72 & 150 & 150 \\
\hline
\end{tabular}

\section{Discussion}

Immunization rate in Nigeria has remained unacceptably low. According to the National Demographic and Health survey (NDHS) 2013, 25\% of Nigerian children are fully vaccinated with BCG, measles and the three doses of DPT/pentavalent and polio vaccines with a range of $1.4 \%$ in Sokoto and $62.4 \%$ in Imo state. Complete vaccination rate was $24.4 \%$ in Ogun state. Urban dwellers have a basic vaccination rate of $42.6 \%$ while rural dwellers have a vaccination rate of $15.8 \%$. The current study shows a complete vaccination rate of $72.2 \%$ This was in agreement with Adeyinka et al who found a vaccination rate of $76.9 \%$ in Igbo-Ora, Oyo state. 9 In Chandigarh, India, complete vaccination rate is $86.4 \%$ as documented by Goel et al. 10 In the current study, the vaccination rate for polio vaccine is over $90 \%$ while that of pentavalent vaccine/DPT is $75-92.3 \%$; vaccination rate for measles vaccines is $55 \%$ while yellow fever vaccination rate $51.9 \%$. The vaccination rate in the current study is quite high compared to the rate in the NDHS but is comparable to the rate obtained by Adeyinka in Nigeria and Goel et al in India.

\section{Mother's Educational Status}

This current study shows a positive relationship between educational status of mothers and immunization of their children. Though not significant for the antigens, it was quite significant for the two doses of vitamin A. This might be because vitamin A is not considered important by less educated mothers. Itimi et al working in a rural community in Bayelsa state found out that for no clear reason, vaccination rate in better educated urban community was much lower than in the rural community $(p<0.001) 11$

\section{Mother's Age}

This study shows a significant relationship between mother's age and immunization of their children. The very young mothers less than 20 years of age tend to have $100 \%$ vaccination rate for most of the vaccines; this equally applies to older mothers who are 50 years of age. The vaccination rate however could be as low as $47.7 \%$ in children of mothers aged between 20-50 years of age. The difference is not statistically significant except for vitamin A1, OPV2, penta2, and penta3. The reason for this is not obvious. This is similar to what Ibnouf et al found in Sudan where children of older mothers were correctly vaccinated more than the children of younger mothers $(82.6 \%$ versus $68.6 \%) .12$

\section{Reasons For Failure To Immunize}


This study shows that the commonest reason given by mothers for failure to vaccinate their children was mother's illness. In the earlier cited study carried out in Igbo-Ora, Adeyinka et al documented that the commonest reason for failure to immunize is long waiting queues $(46.1 \%)$ followed by payment in private clinics $(20.2 \%)$ and distance $(17.7 \%)$.

\section{Conclusionc}

omplete immunization rate observed in this study is commendable, however maternal age, educational status and illness were shown to affect immunization uptake in this rural community.

\section{References}

[1]. Armstrong EP. Economic benefits and costs associated with target vaccination. J Manag Care Pharm 2007; 13:12-15.

[2]. Gains S. Vaccination is the best protection. AAP healthy children's magazine 2009;05-11

[3]. World Health Organization. Challenges in global immunization and its global immunization vision and strategy 2006-2015.Weekly Epidemiol Rec 2006; 19: 190-04

[4]. Otten M, Kezaala R, Fall A, Masresha B, Matin R, Cairris L, et al. Public health impact of accelerated measles control in the WHO African Region Lancet 2005; 369:833-39

[5]. Breiman RF, Streatfield PK, Phelan M, Shifa N, Rasid M, Yunus M. Effect of infant immunization on childhood mortality in rural Bangladesh: Analysis of health and demographic surveillance data. Lancet 2004; 364: 2204-11

[6]. UNICEF. The state of the world's children.UNICEF publication. Oxford University press 2013

[7]. National population Commission, Nigeria. National Demographic Health survey 2013.

[8]. 8.United States Agency for International development. Immunization programmes for healthy children. Immunization basics.

[9]. Goel N, Abrol A, Pathak R, Sharwa M, Gulati S, Swami H. Status of routine immunization in Chindigarh, India. Int J health 2007; 7:34-38

[10]. Adeyinka D, Oladimeji O, Adeyinka F, Aiinakhu C. Uptake of childhood immunization among mothers of under-five in south western Nigeria. Int $\mathbf{J}$ Epidemiol 2008; 28:32-39

[11]. Itimi K, Dienye PO Ordinioha B. Community participation and childhood immunization coverage. A comparative study of rural and urban communities of Bayelsa state, South-South Nigeria.Niger med J 2012; 53: 21-25

[12]. Ibnouf AH, Van den Borne HW, Maarse JAM. Factors influencing immunization coverage among children under five years of age In Khartoum, Sudan.SA FamPract ; 2007; 49:14-20 